\title{
Immune Complexes in Leptospirosis
}

Recent observations (1-2) suggest that Lyme disease, a spirochaetal infection with multisystem involvement, is an immune complex disorder. On the other hand, the pathogenesis of another and more frequent spirochaetal illness, leptospirosis, still remains unclear. In this infection clinical manifestations are protean, varying from asymptomatic cases to a serious hepatorenal disorder known as Weil's disease. We have recently studied the presence of circulating immune complexes (CICs) in eight cases of severe leptospirosis, all due to Leptospira icterohaemorrhagiae. The diagnosis was made by the microagglutination-lysis test on serial serum samples. CICs were investigated by three different methods: $\mathrm{Clq}$ binding assay (C1q-BA) (3), C1q competition assay (C1q-CA) (4), and conglutinin binding competition assay ( $\mathrm{KgB}-\mathrm{CA})(5)$. The results of the determinations are shown in Figure 1.

On admission, all the patients had CICs, detectable by all the techniques employed. In the six patients who survived and were followed-up after the first week of disease, CICs were detectable during the icteric and oliguric period, disappearing as liver and kidney functions improved. Moreover. C3, C4 and CH50 determinations, performed an serial serum samples in four of these patients indicated an activation of the complement system through the classic pathway in the acute phase of the disease. The suggested role of immune complexes in leptospirosis has so far been based on data derived from experimental infections in dogs (6) and from the study of a single human case of Weil's disease (7). Furthermore, immunological mechanisms have been postulated to explain the meningeal involvement which in some patients represents the predominant clinical feature. In our patients, the presence of high concentrations of CICs only during the acute phase of illness seems to confirm that in leptospirosis, as in Lyme disease, immune complex reactions are a significant pathogenetic element.

M. Galli, R. Esposito, P. Crocchiolo, M. Chemotti, M. Gasparro, P. P. Dall'Aglio
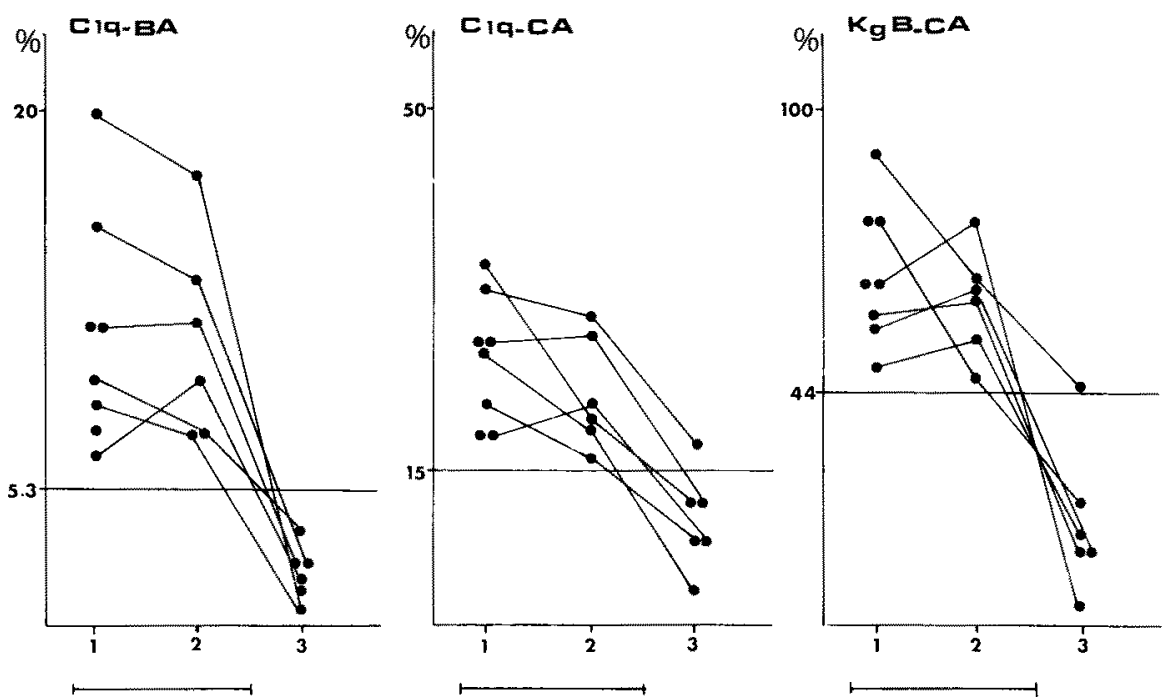

Figure 1: Circulating immune complexes in Weil's disease. 1 = Admission; 2 = Second week of illness; 3 = Recovery; $-=$ Oliguric phase.

\section{Literature}

1. Steere, A. C., Hardin, J. A., Malawista, S. E.: Erythema chronicum migrans and Lyme disease: cryoimmunoglobulins and clinical activity of skin and joints. Science 196 (1977) 121-122.

2. Editorial: Tick-borne Borrelia. Lancet II (1984) 1134-1135.

3. Zubler, R. H., Lange, G., Lambert, P. H., Miescher, P. A.: Detection of immune complexes in unheated sera by a modified ${ }^{125} \mathrm{I}-\mathrm{Cl} q$ binding test: effect of heating on the binding of $\mathrm{Clq}$ by immune complexes and application on the test to systemic lupus erythematosus. J. Immunol. 116 (1976) 232-235.

4. Migliorini, P., Trovatello, G., Cantarella, S., Manca, F., Bombardieri, S., Celada, F.: An enzymatically active antigen-antibody probe to measure circulating immune complexes. E.coli $\beta$-galactosidase in the probe and $\mathrm{Clq}$ as recognition unit. J. Immunol. Meth. $59(1983)$ 245-254.
5. Gnemmi, E., Migliorini, P., Chieregatti, G., Manca, F., Cantarella, S., Celada, F.: A new competitive immunoenzymatic assay to determine circulating immune complexes. J. Res. Lab. Med. 8 (1981) $509-512$.

6. Taylor, P. L., Hanson, L. E., Simon, J.: Serologic, pathologic and immunologic features of experimentally induced leptospiral nephritis in dog. Am. J. Vet. Res. 31 (1970) 1033-1049.

7. Daoudal, P., Mahieu, P., Bloch, B., Barale, F.: Leptospirose avec immunisation anti-membrane basale glomérulaire. Nouv. Presse. Méd. 7 (1978) 3535-3537.

M. Galli, M.D., Assoc. Prof. R. Esposito, M.D., P. Crocchiolo, M.D., Marilynn Chemotti, M.D., Maria Gasparro, Ph.D., Clinic of Infectious Diseases, University of Milan, I-20157 Milan;

Assoc. Prof. P. P. Dall'Aglio, M.D, Chair of Clinical Immunology, University of Parma, I-43100 Parma. 